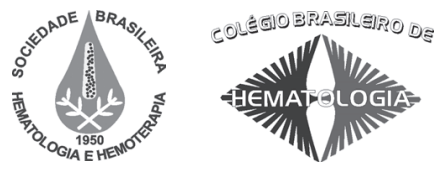

Revisão / Review

\title{
Doenças hematológicas associadas ao eritrovírus
}

\section{Hematologic diseases associated with eritrovirus}

\author{
Sheila O. Garcial \\ Juliana Pereira ${ }^{2}$ \\ Carla R. T. Godoy ${ }^{3}$ \\ Sabri Sanabani ${ }^{4}$ \\ Walter Kleine Neto ${ }^{5}$ \\ Ester C. Sabino ${ }^{6}$
}

\begin{abstract}
O eritrovírus infecta células precursoras eritroides, determinando a interrupção temporária da eritropoese. Neste contexto, é importante o conhecimento das principais doenças hematológicas que podem estar associadas à presença do vírus, principalmente quando estão presentes em condições mórbidas, tais como nas anemias hemoliticas hereditárias. Este trabalho tem como objetivo relatar as principais doenças hematológicas que cursam com a infecção pelo eritrovírus B19. Rev. Bras. Hematol. Hemoter. 2009;31(4):285-290.
\end{abstract}

Palavras-chave: Eritrovírus; diagnóstico; doenças hematológicas.

\section{Introdução}

O eritrovírus humano (parvovírus) B19 foi descoberto na Inglaterra, em 1975, por Yvonne Cossart, ${ }^{1}$ em soro de doadores de sangue cujas amostras foram submetidas a testes sorológicos para diagnóstico do vírus da hepatite B. ${ }^{1}$ Posteriormente sugeriu-se sua associação com diversas síndromes clínicas, a exemplo do eritema infeccioso, crise aplástica de medula óssea, e outros quadros com sintomatologia de mialgia, artralgia e febre. $^{2}$

No Brasil, a primeira menção à infecção por eritrovírus B19 parece ter sido feita em 1983, no qual foram encontrados anticorpos por contraimunoeletroforese em alguns doadores de sangue do Rio de Janeiro. Em 1985, também no Rio de Janeiro, foram encontrados anticorpos anti-B19 por radioimunoensaio em três soros de mulheres grávidas, enviados para detecção de anticorpos contra rubéola. Aparentemente, nenhum destes autores publicou os seus achados, sendo apenas citados em $1989 .{ }^{3}$
Em 1984 foi relatado, na Inglaterra, o primeiro caso de infecção intrauterina por B19. Tratava-se de um caso de hidropisia fetal durante um surto epidêmico de eritema infeccioso. A partir deste relato, documentou-se a potencial toxicidade do eritrovírus B19 aos tecidos embrionários e fetais, agregando mais essa complicação ao grupo das doenças associadas a este agente. ${ }^{2}$ Desde então pode ser feita a associação do vírus com tropismo por células e tecidos, estes com alta taxa de multiplicação celular.

Devido às características estruturais de seu DNA, o eritrovírus foi incluído na família Parvoviridae, subfamília Parvovirinae, gênero Erythrovirus pelo International Committee on Taxonomy of Viruses. ${ }^{4}$ Em 2002 foram descritos os genótipos 1 B19 clássico, genótipo 2, (protótipo K71 e cepa A6-similar) e genótipo 3 (protótipo V9). ${ }^{5}$

Estas novas variantes foram encontradas na Europa Ocidental, EUA e Brasil, mas com menor prevalência que o genótipo $1 .^{5-8}$ Uma região epidêmica de genótipo 3 foi descrita em Ghana. ${ }^{9}, 10$

${ }^{1}$ Bióloga, aluna de pós-graduação do Laboratório de Imunopatologia da Faculdade de Medicina de São Paulo-SP.

${ }^{2}$ Professora colaboradora da Disciplina e Serviço de Hematologia da Faculdade de Medicina da Universidade de São Paulo-SP.

${ }^{3}$ Biomédica do Serviço de Hematologia do Hospital das Clínicas da Faculdade de Medicina da Universidade de São Paulo-SP.

${ }^{4}$ Biomédico. Aluno do curso de pós-doutorado da Faculdade de Medicina de São Paulo-SP.

${ }^{5}$ Biomédico do Serviço de Hematologia do Hospital das Clínicas da Faculdade de Medicina da Universidade de São Paulo-SP.

${ }^{6}$ Médica chefe do setor de Biologia Molecular da Fundação Pró-sangue, Hemocentro, São Paulo- SP.

Faculdade de Medicina da Universidade de São Paulo (USP) - São Paulo-SP.

Correspondência: Sheila de Oliveira Garcia

Avenida Dr. Enéas de Carvalho Aguiar, 155 - $1^{\circ}$ andar, bloco 4, sala 61 - Cerqueira César

Laboratório de Imunopatologia

05403-000 - São Paulo-SP - Brasil

Fone: (55 11)3061-5544 r. 339 - Fax: (55 11)3085-2290

E-mail: sheilagarcia.hp@gmail.com

Doi:10.1590/S1516-84842009005000061 


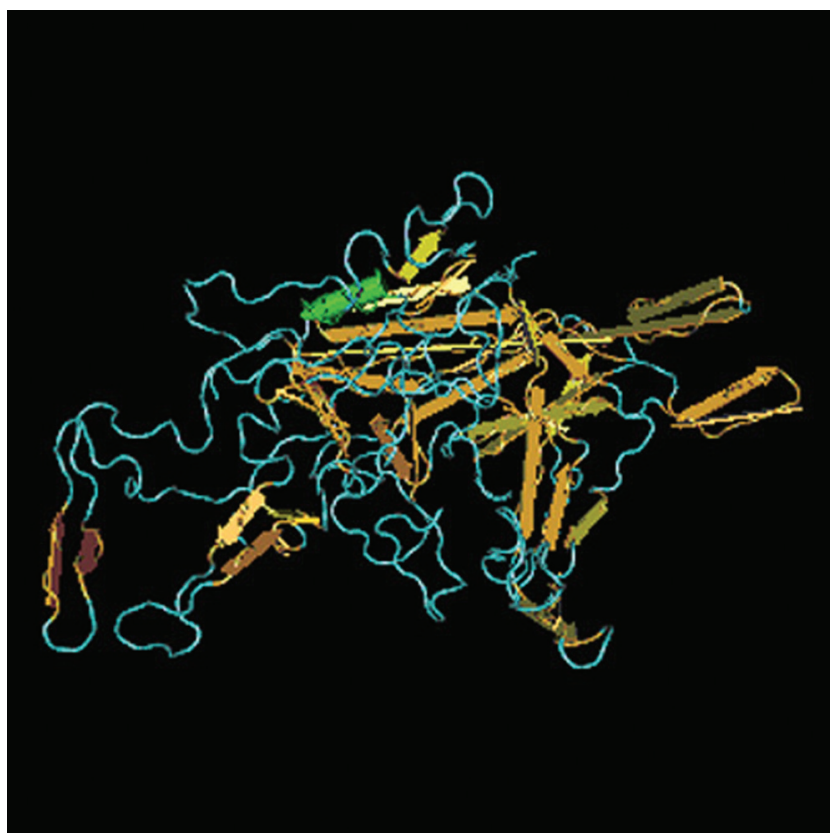

Figura 1. A estrutura do eritrovírus humano B19 (Kaufmann et al.)

\section{Classificação e estrutura viral}

O eritrovírus B19 é um vírus com cerca de $23 \mathrm{~nm}$, de estrutura icosaédrica (Figura 1), constituído por uma única fita de DNA não envelopado. ${ }^{11}$ A classificação na família Parvoviridae é feita por morfologia e função e o material genético constituído por uma fita simples de DNA. ${ }^{12}$

Devido à sua capacidade de infectar células de vertebrados e invertebrados, os Parvoviridae são divididos em Parvovirinae e Densovirinae, respectivamente. O Parvovirinae subdivide-se em gêneros Parvovirus, Dependovirus e Erytrovirus, de acordo com suas peculiaridades genéticas. Somente os membros dos Dependovirus e Erytrovirus causam infecção em humanos. Devido ao alto tropismo para células eritropoéticas, o B19 foi incluído no gênero Erytrovirus, pois se replica apenas em células eritroides da medula óssea (incluindo unidades formadoras de colônia BFU-E - burst forming units erythroid) e do sangue. Como consequência da infecção viral há inibição da eritropoese e efeitos citotóxicos. A infecção inicia-se quando o capsídeo liga-se ao antígeno P. O antígeno P é um glicoesfingolipídeo da linhagem vermelha, especialmente expresso nos proeritroblastos. ${ }^{13}$ É o único vírus desta família conhecido como patogênico para o homem. ${ }^{14,15}$

Portanto, a afinidade do vírus por células progenitoras eritroides deve-se à presença do globosídeo P. Sua adsorção ocorre na região formada por carboidratos do globosídeo ou antígeno ertitrocitário "P" (tetrahexoseramida), conforme Brown et al., em 1993. O antígeno P está presente não só em eritrócitos como também em megacariócitos, células endoteliais, placentárias, hepatócitos e coração fetal.

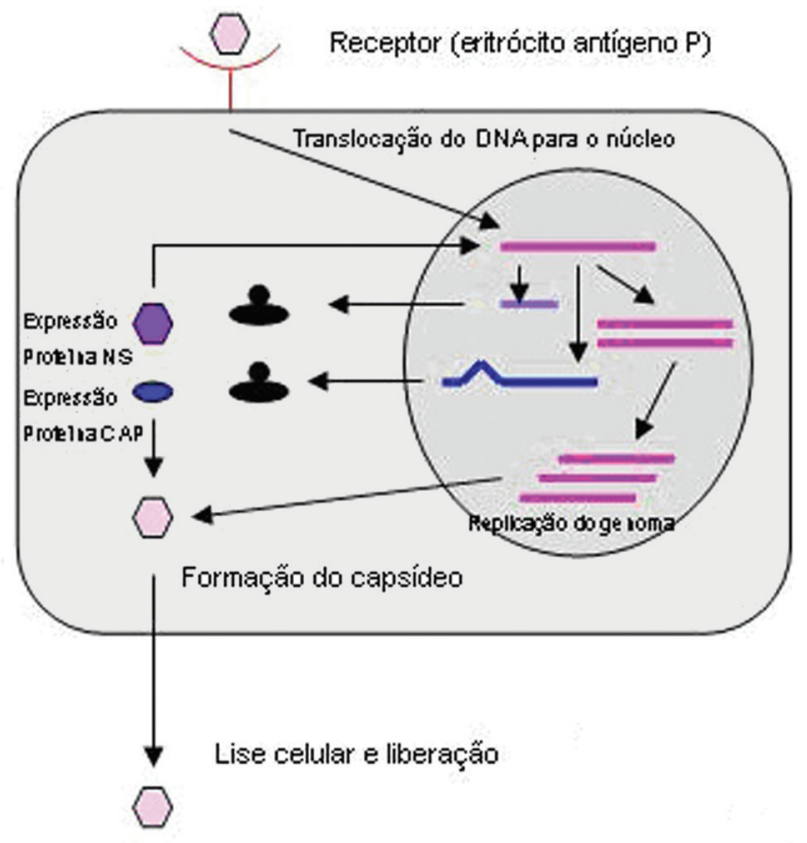

Figura 2. A multiplicação do eritrovírus humano B19 (Adaptada de Kasamatsu e Nakanishi, 1998)

A multiplicação do eritrovírus ocorre nas células precursoras eritroides proliferantes da medula óssea (Figura 2) e fígado fetal. ${ }^{17} \mathrm{O}$ eritrovírus é totalmente dependente do material genético celular para sua multiplicação, pois não codifica proteínas estimuladoras de síntese protéica. $\mathrm{Na}$ extremidade genômica possui palíndromos ou terminações semelhantes a "grampos", estruturas estas que servem como iniciadores de síntese proteica e multiplicação do genoma viral.

$\mathrm{O}$ antígeno $\mathrm{P}$ pode estar ausente numa parcela da população. As estatísticas demonstram que esta ocorrência é razoavelmente rara (1/200.000). Uma vez que não há a presença desta molécula que propicia a ligação e adsorção do vírus para o interior da célula, os indivíduos desprovidos da expressão desta proteína são naturalmente imunes à infecção por eritrovírus B19. ${ }^{15,18}$

A população apresenta quatro grandes grupos de pessoas com diferentes riscos de infecção pelo B19, a saber:

1) indivíduos saudáveis

2) grávidas

3) indivíduos com doenças hematológicas

4) pacientes imunodeprimidos

Os indivíduos saudáveis desenvolvem aplasia eritroide por parada de maturação da eritropoiese medular por cinco a sete dias acompanhada de rash cutâneo e artralgia. As gestantes podem ter aborto e hidropisia fetal. Já os pacientes com doenças hematológicas apresentam quadro caracterizado por anemia aguda; e, finalmente, os imunossuprimidos podem apresentar simplesmente anemia crônica. ${ }^{19-23}$ 


\section{Condições clínicas associadas ao eritrovírus B19}

A maioria das pessoas com eritrovírus B19 são assintomáticas ou apresentam sintomas leves, inespecíficos e associados ao frio, que são manifestações frustras e não patognomônicas de um quadro relacionado à infecção pelo vírus. Entretanto, os pacientes podem ter manifestações clínicas mais exuberantes, tais como o eritema infeccioso, a artropatia, a crise aplástica transitória, a aplasia pura de células vermelhas, a erupção papular, purpúrica em mãos e pés e hidropisia fetal. Algumas manifestações são relacionadas à maior morbimortalidade e são a encefalopatia, epilepsia, meningite, miocardite, cardiomiopatia dilatada e hepatite autoimune. O eritrovírus B19 tem sido sugerido por vários autores como agente causal em várias síndromes clínicas, o que, por vezes, é de difícil comprovação.

A infecção por eritrovírus B19 adquire importância quando acomete portadores de doenças hematológicas hereditárias, tais como as anemias hemolíticas. Nestas doenças, em que o turnover celular é extremamente elevado, a manifestação clínica, no caso a anemia, se torna mais exuberante em função da menor meia vida das hemácias destes pacientes. Como exemplos destacam-se as síndromes falcêmicas, as talassemias, enzimopatias, ou defeitos da membrana eritrocitária, pelo risco de desencadear crise aplástica, ${ }^{24}$ e nos pacientes portadores do HIV, por possibilitar a ocorrência de aplasia eritrocitária pura crônica. Naqueles que, apesar de imunocompetentes, são portadores de patologia hereditária de glóbulos vermelhos, a evolução pode ser para anemia aplástica grave, porém reversível. Embora a aplasia transitória seja, geralmente, autolimitada, os pacientes podem apresentarse extremamente debilitados e evoluir para óbito caso a correção da anemia não seja iniciada prontamente. ${ }^{13}$

\section{Eritema infeccioso (Quinta doença)}

O eritema infeccioso é a infecção causada pelo eritrovírus B19 humano mais frequentemente reconhecida, geralmente em crianças de 4 a 10 anos de idade. Caracteriza-se por febre, cefaléia e eritema facial intenso, circunscrito, com aparência de face esbofeteada que, após alguns dias, dissemina-se para tronco e membros, e frequentemente confunde-se com rubéola. ${ }^{25}$

\section{Crise aplástica transitória}

Pessoas com menor quantidade de eritrócitos por uma série de fatores, tais como: deficiência de ferro, infecção pelo vírus da imunodeficiência humana (HIV), doença falciforme, esferocitose, talassemia e anemia hemolítica autoimune (AHAI) têm maior risco de desenvolverem crise aplástica transitória (CAT) por eritrovírus B19. O vírus bloqueia transitoriamente a produção de eritrócitos, com risco de morte, embora a maior parte dos casos apresente recuperação em duas semanas, mas com necessidade de múltiplas transfusões inicialmente. Há redução abrupta da hemoglobina, dos reticulócitos e precursores eritroides na medula óssea, com ou sem plaquetopenia e leucopenia. A redução abrupta da hemoglobina cursa com anemia aguda. A presença do quadro de anemia aguda pode causar insuficiência cardíaca congestiva, dita cor anêmica, acidente vascular cerebral por hipofluxo ou baixo fluxo cerebral, e sequestro esplênico agudo. Pode haver plaquetopenia e leucopenia. ${ }^{26}$

Durante a CAT, o paciente está agudamente infectado e elimina enormes quantidades de vírus por via respiratória, constituindo-se numa fonte potencial de infecção nosocomial. Nesta fase, os pacientes têm alta probabilidade de transmitir a infecção para outros indivíduos e devem ser mantidos em isolamento respiratório. ${ }^{12,27}$

Em 1981, na cidade de Londres, foi descrita a viremia por eritrovírus em duas crianças; este estudo demonstrou a presença dos antígenos B19 e/ou de anticorpos IgM indicativos de infecção aguda em mais de 800 soros estocados. Surpreendentemente, foram encontradas antigenemia ou soroconversão em seis outras amostras, todas de crianças portadoras de doença falciforme, imigrantes da Jamaica, que haviam sido admitidas com CAT. ${ }^{28}$ Também em 1981, a soroconversão e elevação significativa dos títulos ou a presença de partículas virais foram demonstradas em 24 de 28 soros obtidos de crianças jamaicanas portadoras de anemia falciforme com CAT, com a qual o vírus foi finalmente associado como agente causal. Atualmente, o eritrovírus B19 é considerado a mais importante causa de CAT em doença falciforme. ${ }^{27}$

\section{Aplasia pura da Série Vermelha}

A infecção por eritrovírus B19 pode ser persistente nos imunossuprimidos. Estes indivíduos apresentam déficit isolado e/ou combinado de imunidade. A repercussão mais crítica é nos pacientes com imunossupressão da imunidade humoral, na qual há redução ou ausência da síntese de anticorpos. Com relação ao eritrovírus, é importante que sejam estabelecidos anticorpos específicos para combate à infecção. Portanto, rashes e artropatia não se desenvolvem, pois estes ocorrem devido à deposição de complexos e anticorpos na pele e nas articulações. Os pacientes têm fadiga e palidez por anemia, a qual pode ser grave, prolongada ou recorrente. Em pacientes com HIV, o uso de anti-retroviral pode melhorar os sintomas, como exemplo o AZT. O tratamento da anemia pode ser feito com a aplicação intravenosa de gamaglobulina humana padrão, que geralmente contém anticorpos em quantidade suficiente para debelar a viremia. ${ }^{27}$

\section{Hidropisia fetal}

Durante o desenvolvimento fetal, alguns anticorpos podem provocar hemólise no feto por diversas razões; em 
casos muito graves desenvolve-se hidropisia fetal, caracterizada por ascite, edema generalizado, hepatomegalia, esplenomegalia e prognóstico fatal, geralmente a IgG é que ultrapassa a placenta. ${ }^{29}$

A primeira associação entre infecção por eritrovírus B19 e complicações na gravidez foi descrita em 1984, quando se demonstrou presença de imunoglobulina M (IGM) anti-B19 em fetos. $^{2}$

Embora o B19 não tenha efeito adverso para a saúde da mulher grávida, a transmissão transplacentária para o feto é importante causa de morte fetal intrauterina. A maioria dos danos secundários ao vírus ocorre no primeiro trimestre de gravidez. ${ }^{2}$

A taxa de transmissão do vírus para o feto é de $33 \%$ e o risco de morte pode ser de $0 \%$ a $9 \%$. A manifestação clínica mais comum é a hidropisia fetal não imune. Muitos casos de hidropisia causam ao feto anemia aplástica, falência cardíaca e miocardite. O eritrovírus é responsável por $10 \%$ dos casos de hidropisia fetal por anemia hemolítica. A imunidade após infecção está presente em $50 \%$ das mulheres em idade fértil soropositivas (IgG) com ausência de $\operatorname{IgM}$, indicando infecção prévia assintomática ou sintomática. ${ }^{30}$

\section{Artropatia}

Artropatia pode ser complicação de eritema infeccioso ou apresentação primária de infecção por eritrovírus; cerca de $8 \%$ das crianças infectadas têm artralgia. Entretanto, a artralgia é mais comum em adolescente e adulto com infecção por eritrovírus B19, acometendo $60 \%$ das pessoas. É duas vezes mais frequente em mulheres do que em homens. ${ }^{21}$

\section{Síndrome gloves and socks (luvas e meias)}

O eritrovírus B19 está associado à síndrome gloves and socks, caracterizada por eritema e edema simétrico em pés e mãos, mais frequentemente em adultos jovens. Gradualmente evolui para petéquias e púrpura, podendo chegar à formação de vesículas e bolhas. O marco desta síndrome é a presença de rash delimitando o umbigo e tornozelo. Concomitantemente pode haver artralgia, febre, ou ambos, e a resolução dos sintomas ocorre em uma a três semanas. Esta síndrome também pode ser causada pelo vírus da hepatite $\mathrm{B}$, citomegalovírus, herpesvírus humano 6 , coxsackievírus $\mathrm{B}$ e drogas. ${ }^{31}$

\section{Síndrome hemofagocítica}

A síndrome hemofagocítica associada a vírus (VAHS) é uma doença rara caracterizada por ativação e proliferação de macrófagos dentro na medula óssea (MO). Macrófagos ativados na MO fagocitam eritrócitos, leucócitos, plaquetas e seus precursores causando citopenias. Os critérios diagnósticos desta síndrome incluem febre, hepatoesplenomegalia, linfadenomegalia e rash. Laboratorialmente pode haver pancitopenia, disfunção hepática, coagulação intravascular disseminada, hipertrigliceridemia e anormalidades de MO. Em geral está associada a várias infecções virais, como vírus EpsteinBarr (EBV) e eritrovírus B19. ${ }^{32}$

\section{Persistência do eritrovírus em pessoas saudáveis}

Conforme Lefrere et al., em indivíduos imunocompetentes o eritrovírus pode ser detectável vários anos após a infecção. A persistência de infecção pelo vírus em medula também foi documentada em indivíduos imunocompetentes com ou sem sintomas.

Recentes estudos têm demonstrado que grande parte da população adulta mostra evidências de exposição anterior ao eritrovírus. Embora a resposta imune seja capaz de neutralizar a infecção ao longo da vida e proporcionar proteção contra o vírus, em muitos indivíduos ocorre à persistência viral no sangue ou outros tecidos, independente da imunocompetência do hospedeiro. ${ }^{37}$

A prevalência de DNA em indivíduos adultos saudáveis é de $0,5 \%$ a $9,0 \%$, e a frequência da viremia foi estimada de 1:13 a 1:180, conforme estudo realizado em amostras de soro ou plasma por Lefrere et al. e Candotti et al. entre os anos de 1999 a 2005, em cerca de 2.500 doadores saudáveis (Tabela 1).

Embora o anticorpo seja prevalente em grande parte da população, a presença de DNA viral ou viremia é rara. ${ }^{36}$

\section{Diagnóstico}

O diagnóstico da infecção por eritrovírus B19 pode apresentar dificuldades no paciente imunodeprimido. Embora a prevalência de anticorpos IgM e IgG pareça ser maior nos pacientes com doenças de imunossupressão, tais como a síndrome da imunodeficiência adquirida (AIDS), do que na população em geral, num determinado paciente com aplasia pura de células vermelhas, os anticorpos podem ser totalmente ausentes, ou se apresentarem apenas sob a forma de baixos títulos de IgM. O diagnóstico exige técnicas de maior sensibilidade. Neste contexto, o recurso laboratorial

Tabela 1. Presença do DNA do eritrovírus em doadores saudáveis entre 1999 a 2005

\begin{tabular}{ccccc}
\hline $\begin{array}{c}\text { Local do } \\
\text { Estudo }\end{array}$ & $\begin{array}{c}\text { Tipo de } \\
\text { Material }\end{array}$ & $\begin{array}{c}N^{\circ} \text { Total de } \\
\text { Amostras }\end{array}$ & $\begin{array}{c}\text { DNA do } \\
\text { Eritrovírus }\end{array}$ & $\begin{array}{c}\text { Prevalência } \\
\text { DNA }\end{array}$ \\
\hline Reino Unido & Soro ou plasma & 1.000 & 9 & $0,90 \%$ \\
Ghana & Soro ou plasma & 1.000 & 13 & $1,29 \%$ \\
África do Sul & Soro ou plasma & 360 & 2 & $0,50 \%$ \\
Malawi & Soro ou plasma & 80 & 1 & $1,25 \%$ \\
França & Soro & 76 & 6 & $7,90 \%$ \\
\hline Total & & 2516 & 31 & $1,23 \%$ \\
\hline
\end{tabular}


pode ser apoiado pela pesquisa do vírus através de PCR, hibridização in situ, ou de proteínas no dot blot, e imunohistoquímica com anticorpos monoclonais em tecidos de amostras colhidos dos pacientes em casos específicos e selecionados. ${ }^{27}$

Em pacientes imunossuprimidos com infecção crônica e em pacientes com crise aplástica transitória, o exame de DNA viral é importante para o diagnóstico de infecção por eritrovírus B19. Estes pacientes podem não apresentar IgM ou IgG no soro, mas persistem com alta taxa de transmissão. Neste contexto faz-se útil a pesquisa propriamente do vírus e não do seu anticorpo. Um dos métodos mais empregados é a Reação em Cadeia da Polimerase (PCR); sua sensibilidade e especificidade podem variar, mas ainda assim a técnica de PCR é mais sensível que a pesquisa de IgM. Os pacientes imunossuprimidos podem ter uma carga viral alta dentro da célula, porém o mecanismo de demonstrar reatividade pela presença de anticorpos e pela $\operatorname{IgM}$, no caso os pacientes imunossuprimidos, tem redução ou não tem $\operatorname{IgM}$, o que favorece então o papel de pesquisar o vírus por outros métodos. ${ }^{33}$ Portanto, faz-se necessário que outros métodos complementem a abordagem da investigação diagnóstica. $\mathrm{O}$ paciente imunossuprimido tem uma debilidade de resposta imune, o que faz com que não tenha IgM ou tenha muito pouca. Consequentemente, o paciente pode ter anemia persistente, que pode ser o parâmetro clínico observado pelo médico; no momento seguinte, em conjunto com reticulocitopenia, o médico pensa em infecção por B19 e pede IgM. A IgM vem negativa para eritrovírus, o médico continua a achar que é infecção por B19, mas vale ressaltar que pode ter uma viremia elevada e debilidade na produção de anticorpo. Se não for feito o PCR, ou a cultura de vírus, a anemia pelo B19 poderá não ser diagnosticada neste contexto. ${ }^{34}$

\section{Tratamento}

Em geral, o eritema infeccioso é autolimitado e não requer tratamento específico. Situações clínicas onde o contexto é mais complexo exigem uma abordagem clínica aprofundada e baseada em evidências científicas. Os pacientes com artrite e artralgia podem necessitar de controle da dor e do edema através do uso de drogas, como os antiinflamatórios não esteroides. Os pacientes com crise aplástica necessitam transfusão de hemácias entre o período de recuperação medular. A taxa de hemoglobina varia, mas é importante salientar que, na instalação da anemia aguda, os pacientes não costumam ter tolerância cardiovascular e, portanto, a correção visa manter a hemoglobina em níveis por volta de $10 \mathrm{~g} / \mathrm{dL}$. Nas situações onde os pacientes não têm anticorpos ou apresentam uma resposta inadequada, tal como a aplasia crônica da série vermelha grave, pode ser necessária infusão de imunoglobulina humana. A imunoglobulina humana é eficaz, porém, como um hemoderivado, contém proteínas, o que pode precipitar rash e artropatia.
Não existe ainda uma vacina disponível licenciada para a prevenção da infecção. ${ }^{35}$

\section{Discussão}

Os pacientes com eritrovírus B19 persistente podem se beneficiar com terapia com imunoglobulina intravenosa imune.

Gestantes com diagnóstico de infecção por eritrovírus B19 devem receber ultrassonografia seriada semanalmente duas vezes por semana por 10 a 12 semanas, devido às complicações causadas acerca da infecção.

O padrão ouro de diagnóstico até o momento é a biologia molecular, no qual o teste da reação da polimerase em cadeia (PCR) é o mais preciso para a detecção e identificação das variantes do vírus.

É importante lembrar que vários estudos estão voltados para a genotipagem, pois é bastante discutido o significado das variantes dos eritrovírus e sua relação com as doenças hematológicas.

\begin{abstract}
Erythroviruses infect precursor erythroid cells, determining a temporary disruption of erythropoiesis. Thus, knowledge of the main hematological diseases that may be associated with the virus is important, especially when they are present in morbid conditions, such as in hereditary hemolytic anemia. This paper aims at reporting the main hematological diseases that are associated with erythrovirus infections. Rev. Bras. Hematol. Hemoter. 2009;31 (4): 285-290.
\end{abstract}

Key words: Erythrovirus; diagnostic; hematologics diseases.

\section{Agradecimentos}

À Fundação de Amparo a Pesquisa do Estado de São Paulo (Fapesp).

\section{Referências Bibliográficas}

1. Cossart YE, Field AM, Cant B, Widdows D. Parvovirus-like particles in human sera. Lancet. 1975;1(7898):72-3.

2. Brown T, Anand A, Ritchie LD, Clewley JP, Reid TM. Intrauterine parvovirus infection associated with hydrops fetalis. Lancet. 1984; 2(8410):1033-4.

3. da Silva Cruz A, Serpa MJ, Barth OM, do Nascimento JP. Detection of the human parvovirus B19 in a blood donor plasma in Rio de Janeiro. Mem Inst Oswaldo Cruz. 1989;84(2):279-80.

4. Siegl G, Bates RC, Berns KI, Carter BJ, Kelly DC, Kurstak E, et al. Characteristics and taxonomy of Parvoviridae. Intervirology. 1985;23(2):61-73.

5. Servant A, Laperche S, Lallemand F, Marinho V, De Saint Maur G, Meritet JF, et al. Genetic diversity within human erythroviruses: identification of three genotypes. J Virol. 2002;76(18):9124-34. 
6. Wong S, Young NS, Brown KE. Prevalence of parvovirus B19 in liver tissue: no association with fulminant hepatitis or hepatitisassociated aplastic anemia. J Infect Dis. 2003;187(10):1581-6.

7. Cohen BJ, Gandhi J, Clewley JP. Genetic variants of parvovirus B19 identified in the United Kingdom: implications for diagnostic testing. J Clin Virol. 2006;36(2):152-5

8. Sanabani S, Neto WK, Pereira J, Sabino EC. Sequence variability of human erythroviruses present in bone marrow of Brazilian patients with various parvovirus B19-related hematological symptoms. J Clin Microbiol. 2006;44(2):604-6.

9. Candotti D, Etiz N, Parsyan A, Allain JP. Identification and characterization of persistent human erythrovirus infection in blood donor samples. J Virol. 2004;78(22):12169-78.

10. Parsyan A, Kerr S, Owusu-Ofori S, Elliott G, Allain JP. Reactivity of genotype-specific recombinant proteins of human erythrovirus B19 with plasmas from areas where genotype 1 or 3 is endemic. J Clin Microbiol. 2006;44(4):1367-75.

11. Kaufmann B, Simpson AA, Rossmann MG. The structure of human parvovirus B19. Proc Natl Acad Sci USA. 2004; 101 (32):11628-33.

12. Costa FF. Anemia Falciforme. In: Zago MA, Falcão RP, Pasquini R. Hematologia. Fundamentos e Prática. $1^{\mathrm{a}}$ ed. Rio de Janeiro:

13. Valera ET, Cipolotti R, Bernardes JE, Pacagnella RC, Lima DM, Tone LG, et al. Pancitopenia transitória induzida por parvovírus B19 em criança portadora de esferocitose hereditária. J Pediatr. 2000;76(4):323-6.

14. Azzi A, Morfini M, Mannucci PM. The transfusion-associated transmission of parvovirus B19. Transfus Med Rev. 1999;13 (3):194-204.

15. Araújo F, Koch MC, Monteiro F, Araújo AR. A infecção pelo parvovírus B19. Acta Med Portuguesa. 1999;12:195-202.

16. Brown KE, Anderson SM, Young NS. Erythrocyte P antigen: cellular receptor for B19 parvovirus. Science. 1993;262(5130): 114-7.

17. Kasamatsu H, Nakanishi A. How do animal DNA viruses get to the nucleus? Annu Rev Microbiol. 1998;52:627-86.

18. Godinho C, Costa M, Alegria A, Coimbra E. Infecção por parvovírus B19 - revisão bibliográfica. Rev Pot Doenc Infec. 1994;4:215

19. Wakamatsu C, Takakura F, Kojima E, Kiriyama Y, Goto N, Matsumoto $\mathrm{K}$, et al. Screening of blood donors for human parvovirus B19 and characterization of the results. Vox Sang. 1999;76(1):14-21.

20. Santagostino E, Mannucci PM, Gringeri A, Azzi A, Morfini M. Eliminating parvovirus B19 from blood products. Lancet. 1994; 343(8900): 798 .

21. Siegl G, Cassinotti P. Presence and significance of parvovirus B19 in blood and blood products. Biologicals. 1998;26(2):89-94.

22. Prowse C, Ludlam CA, Yap PL. Human parvovirus B19 and blood products. Vox Sang. 1997;72(1):1-10.

23. Aubin JT, Defer C, Vidaud M, Maniez Montreuil M, Flan B. Largescale screening for human parvovirus B19 DNA by PCR: application to the quality control of plasma for fractionation. Vox Sang. 2000;78(1):7-12.

24. Young N. Hematologic and hematopoietic consequences of B19 parvovirus infection. Semin Hematol. 1988;25(2):159-72.

25. Veronesi, R; Focaccia, R. Tratado de infectologia: v.1. Säo Paulo, Atheneu, 2002. p.486-490.

26. Saarinen UM, Chorba TL, Tattersall P, Young NS, Anderson LJ, Palmer E, et al. Human parvovirus B19-induced epidemic acute red cell aplasia in patients with hereditary hemolytic anemia. Blood. 1986;67(5):1411-7.
27. Setúbal S, Oliveira SA, Angelis FD, Serôdio AC, Nascimento JP. Manifestações clínicas associadas ao parvovírus B19, incluindo a anemia persistente na AIDS e em outras formas de imunodepressão. J Bras Doenças Sex Transm. 2001;13(4):55-60.

28. Pattison JR, Jones SE, Hodgson J, Davis LR, White JM, Stroud CE, et al. Parvovirus infections and hypoplastic crisis in sickle-cell anaemia. Lancet. 1981;1(8221):664-5.

29. Amico ED, Daniel MM, Silveira PAA, Buccheri V. Manual de Hematologia Propedêutica e Clínica. $3^{\text {a }}$ ed. São Paulo: Medsi; 2003. p.356.

30. Xu J, Raff TC, Muallem NS, Neubert AG. Hydrops fetalis secondary to parvovirus B19 infections. J Am Board Fam Pract. 2003; 16 (1):63-8.

31. Bagot M, Revuz J. Papular-purpuric "gloves and socks" syndrome: primary infection with parvovirus B19? J Am Acad Dermatol. 1991;25(2 Pt 1):341-2.

32. Boruchoff SE, Woda BA, Pihan GA, Durbin WA, Burstein D, Blacklow NR. Parvovirus B19-associated hemophagocytic syndrome. Arch Intern Med. 1990;150(4):897-9.

33. Brown KE, Hibbs JR, Gallinella G, Anderson SM, Lehman ED, McCarthy $\mathrm{P}$, et al. Resistance to parvovirus B19 infection due to lack of virus receptor (erythrocyte P antigen). N Engl J Med. 1994;330(17):1192-6.

34. Florea AV, Ionescu DN, Melhem MF. Parvovirus B19 infection in the immunocompromised host. Arch Pathol Lab Med. 2007; 131 (5):799-804.

35. Young NS, Brown KE. Parvovirus B19. N Engl J Med. 2004; 350(6):586-97.

36. Lefrère JJ, Servant-Delmas A, Candotti D, Mariotti M, Thomas I, Brossard Y, et al. Persistent B19 infection in immunocompetent individuals: implications for transfusion safety. Blood. 2005; 106 (8):2890-5

37. Parsyan A, Candotti D. Human erythrovirus B19 and blood transfusion - an update. Transfus Med. 2007;17(4):263-78.

38. Candotti D, Etiz N, Parsyan A, Allain JP. Identification and characterization of persistent human erythrovirus infection in blood donor samples. J Virol. 2004;78(22):12169-78.

Avaliação: Editor e dois revisores externos Conflito de interesse: sem conflito de interesse.

Recebido: $15 / 6 / 2008$

Aceito: 22/01/2009 